\title{
CULTURAL GEOGRAPHY
}

The AAG Committee on Cultural Geography, in conformity with the resolutions adopted at the Columbus meetings, invites potential authors to submit topics for papers to be precirculated and discussed at its open sessions during the Toronto meetings, September 1966.

Two half-day programs are being planned, each comprising five presentations, respectively in General Cultural Geography, and the Cultural Geography of North America. The program will consist in each case of a discussion of papers previously distributed.

In order to facilitate selection of topics and papers, the Committee requests that provisional abstracts, not over 250 words long, be submitted. (Abstracts should be sent to P. L. Wagner, Dept. of Geography, University of California, Davis, California 95616.) Respondents will be notified individually of action taken. The Selections will be announced in a later issue of The Professional Geographer.

The Committee will arrange for reproduction and distribution of the papers, which will be made available in advance of the meetings at a price to be announced.

\section{TORONTO MEETINGS}

The 1966 annual meeting of the American Association of Geographers will be held at the Royal York Hotel in Toronto, Canada, from Sunday, August 28th to Wednesday, August 31st. Plans have been made to hold a four-day field trip to northern Ontario during the week before the convention. A two-day field excursion into eastern Ontario is also planned. Field trips to the Niagara Peninsula and Waterloo County and daily bus and walking excursions in metropolitan Toronto will be provided. It is hoped that a reconnaissance of the Toronto region from the air will also be available. Details of all field trips, along with registration forms, will be mailed directly to members of the Association in the spring. On most trips, and particularly the northern and eastern Ontario trips, and the air recon- naissance, participation will be limited to early registrants.

The Royal York is a large hotel and several hundred rooms have been reserved for the delegates. In addition, rooms have been reserved for graduate students and junior lecturers (married and single quarters) at residences on the campus of the University of Toronto which is only ten minutes in travel time by subway from the convention hotel.

Detailed information on accommodations, recreation facilities, and tourist attractions will be mailed directly to members of the Association in the spring.

Donald Kerr,

Organizing Secretary,

Local Arrangements Committee

\section{PAPERS FOR THE TORONTO MEETINGS}

Members who intend to submit papers to the Program Committee for the Toronto Meetings are advised to read carefully the specifications in The Professional Geographer, December, 1965, issue, to ascertain the proper form and number of copies for paper and abstract.

The closing date of April 15, 1966, is necessary in order that papers may be read by members of the Program Committee, discussed in general session, the structure of the program formulated, and section chairmen appointed in time for program printing. Papers received more than a few days after the April 15th deadline cannot be processed and must be returned to the writers.

Charles M. Davis,

Chairman, Program Committee Department of Geography

University of Michigan Ann Arbor, Michigan 